\title{
Assistente ou Secretário Executivo? Um Estudo de Caso Sobre Assessorias Complexas
}

\section{Assistant or Executive Secretary? A Case Study on Complex Advisory}

Viviane Alessandra Rodrigues da Silva ${ }^{1}$, Aurélia Moteka Batista de Queiroz Mott ${ }^{2}$ e Aline Cantarotti ${ }^{3}$

1,2,3 Universidade Estadual de Maringá, UEM 


\title{
Resumo
}

Este estudo de caso teve como objetivo analisar as atividades desenvolvidas pelo profissional de Secretariado Executivo em uma organização de médio porte e compará-las com as atividades de superintendentes, ou assessores de alto nível, confirmando, assim, se o Secretário Executivo, no caso analisado, utiliza competências para desempenhar atividades de assessorias complexas, extrapolando a atuação puramente técnica. Os dados foram obtidos por meio de observação participante e entrevistas in loco, além da análise bibliográfica de publicações na área. Realizou-se a análise de conteúdo categorial e a triangulação dos dados triangulados, a fim de elaborar conclusões sobre o caso. Os principais achados revelam que, em teoria, o profissional de Secretariado Executivo está apto a realizar assessoria em níveis complexos, conforme defendido pelas pesquisas da área. Porém, no caso analisado, o exercício da profissão não condiz com o preconizado pelas teorias. A partir da identificação de múltiplas possibilidades da assessoria, evidenciadas na prática de uma organização real, ressaltam-se competências necessárias ao profissional que busca assessorar em funções complexas, destacando o desenvolvimento de conhecimento estratégico e mercadológico de atuação da empresa. Esta pesquisa sugere caminhos para os profissionais que desejam ampliar seu campo de atuação, oferecendo novas perspectivas para a prática secretarial que certamente implicam em novos desafios.

Palavras-chave: secretariado executivo, assessorias complexas, competências secretariais, estudo de caso

\begin{abstract}
This case study aimed to analyze the activities developed by the Executive Secretariat professional in a medium-sized organization and compare them with the activities of superintendents, or high-level advisers, thus confirming whether the Executive Secretary, in the case analyzed, uses skills to perform complex advisory activities, extrapolating purely technical performance. The data were obtained in the organization through participant observation and interviews, in addition to the bibliographic analysis of publications in the area. Then, they were verified by categorical content analysis and triangulated in order to draw conclusions about the case. The main findings reveal that, in theory, the Executive Secretariat professional is able to advise at complex levels, as advocated by research in the area. However, in the case analyzed, the professional performance does not match what is observed in the theories. Based on the identification of multiple advisory possibilities, evidenced in the practice of a real organization, the necessary skills are highlighted for the professional who seeks to assist in complex functions, highlighting the development of strategic and market knowledge of the company's performance. This study suggests ways for professionals who wish to expand their field of action, offering new perspectives for secretarial practice that certainly imply new challenges.
\end{abstract}

Keywords: executive secretary, complex advisory, secretarial competences, case study 
As pesquisas na área de Secretariado Executivo destacam a multifuncionalidade deste profissional que atua, principalmente, como assessor dentro das organizações (Nonato Junior, 2009; Durante, 2012; Camargo et al., 2015). Tais perspectivas teóricas pressupõem que o Secretário Executivo possui competências para assumir funções de assessorias diversificadas dentro de uma organização, em seus vários níveis de complexidade, exigindo do profissional competências múltiplas e conhecimentos multidisciplinares (Nonato Junior, 2009).

Atualmente, a literatura resultante das pesquisas da área secretarial defende que este profissional é capaz de assessorar tanto em níveis técnicos quanto em níveis mais complexos. Denominam-se, neste artigo, assessorias complexas as funções de assessoria que incluem tarefas dentro do ambiente organizacional nas esferas de cogestão, possibilitando tanto a assessoria à tomada de decisão de um modo geral, além da intermediação nos níveis estratégicos e tático-operacionais dentro de uma organização.

Lasta e Durante (2011, p. 06) afirmam que o Secretário:

"Ainda é um negociador, programador de soluções, empreendedor, mostrando iniciativa, proatividade, comprometimento e participando em inúmeras atividades no ambiente de trabalho. Nesta perspectiva, o Secretário é um ser capaz de pensar estrategicamente, promover mudanças e não apenas cumprir/executar tarefas e ordens."

Moreira et al (2016) confirmaram, em âmbito teórico, forte correlação entre as funções e competências do Secretário Executivo e das gerências intermediárias, denominadas, por estes autores, posições de Middle Managers, ou gerentes intermediários.

Entretanto, na prática, ainda não está consolidado o reconhecimento deste profissional em todos os níveis de assessoria (Camargo et al., 2015). As múltiplas funções das assessorias (Nonato Junior, 2009) nem sempre são relacionadas ao profissional graduado em Secretariado Executivo. O mercado de trabalho, e a sociedade como um todo, por vezes compreende esta profissão de forma reducionista, limitando sua função à de assistente pessoal ou departamental, fortemente atrelada à uma atuação técnica. No entanto, é cada vez mais comum profissionais formados em Secretariado assumirem posições complexas nas empresas, porém em outros cargos (gestor, supervisor, analista etc.).

Antes de questionar as razões para esta compreensão simplista do profissional, a fim de sugerir possibilidades para que ele seja também reconhecido como capaz de atuar em assessorias de níveis mais complexos, como defende a literatura, é necessário confirmar se o profissional contemporâneo está apto a assumir tais funções.

Visando contribuir nesse sentido, a presente pesquisa investiga a atuação das assessorias, em seus diferentes níveis, na prática cotidiana de uma organização. Trata-se da filial de uma cooperativa nacional, de médio porte, localizada no estado do Paraná. Fundada há mais de 55 anos, com o objetivo de organizar a produção regional de café. Com o passar do tempo, ela cresceu e diversificou seus negócios. Presente em vários municípios do país, a organização conta com mais de 10 mil associados voltados para a produção de soja, milho, trigo, café, laranja, entre outros produtos. 
A organização é voltada para as vendas, tanto no varejo quanto no atacado, com linhas de produção denominadas: tradicionais, gourmet, agrícola, de sementes, pecuária, rações e suplementos. Além disso, trabalha com programas de melhoria contínua para aprimorar seus produtos, como Lean Six Sigma, Kaizen e um programa da qualidade próprio da empresa.Recebeu vários prêmios em seu segmento, relacionados às áreas de inovação em tecnologia da informação, sustentabilidade, agronegócio, meio ambiente, Top of Mind (Revista Exame) e troféu de melhor indústria.

A partir de um estudo de caso, pela triangulação dos dados obtidos por observação participante, entrevistas e análise documental, busca-se esclarecer a seguinte questão: o Secretário Executivo está apto a assumir funções de assessoria em níveis complexos, como cogestor e tomador de decisão na assessoria a altos Executivos, dentro da organização estudada?

Objetiva-se, assim, confrontar as competências do profissional de Secretariado Executivo descritas na literatura e observadas na prática organizacional, com as de funções que se assemelham a assessorias complexas dentro da organização, buscando compreender se o Secretário Executivo, no caso estudado, tem capacidade de desempenhar atividades complexas.

Especificamente, objetiva-se analisar a função e as competências exigidas dos profissionais no cargo de superintendentes na organização estudada. Considerando que tais profissionais são gestores, com poder de decisão estratégica e operacional, que assessoram o mais alto nível de diretoria executiva da organização, o que configura uma função semelhante às assessorias complexas na empresa; e comparar estas competências com as do profissional de Secretariado Executivo, identificadas pela literatura da área e observadas na atuação dos Secretários Executivos na empresa estudada.

Atualmente discute-se que a função de assessoria executiva, principalmente quando esta é reduzida a funções tecnicistas, corre o risco de se tornar desnecessária. Como as organizações contemporâneas (Choo, 2003) priorizam a redução de custos, também por meio da redução da mão de obra, a elevada automação e informatização na era da informação e a autonomia dos Executivos modernos podem contribuir para acentuar este o risco.

Nesse sentido, a compreensão do que as organizações esperam de profissionais em níveis complexos de assessoria torna-se imprescindível para que o Secretário Executivo se fortaleça no mercado como um profissional indispensável, e que agrega valor para a organização.

Adicionalmente, os resultados desta investigação evidenciam as competências necessárias para um profissional assumir estas funções de assessorias complexas, abrindo caminhos para pesquisas futuras que identifiquem em quais delas os profissionais de Secretariado praticam e quais ainda devem ser consolidadas como competência. Estes achados permitem identificar os possíveis desafios da academia e dos profissionais para a formação na área secretarial, além de apresentar como são aplicados na prática os conhecimentos e competências pelo profissional de Secretariado no estudo em questão. 
Ressalta-se que a presente pesquisa foi devidamente aprovada pelo Comitê Permanente de Ética em Pesquisa (COPEP) envolvendo seres humanos da Universidade Estadual de Maringá, conforme Parecer Consubstanciado do CEP, sob o número: 018836/2019.

\section{Referencial Teórico}

\section{Atuação do Profissional de Secretariado}

O mercado de trabalho está cada vez mais exigente. A demanda por profissionais qualificados tem se tornado mais rigorosa. Buscam-se profissionais completos que acompanhem o crescimento e a evolução do mercado e das empresas.

O profissional de Secretariado Executivo possui uma imagem, na sociedade em geral, limitada à do assistente pessoal ou departamental, facilitador de tarefas puramente técnicas e operacionais. Entretanto, a literatura indica mudanças neste cenário. Para Santos e Cruz (2012, p. 03), a atuação deste profissional se apresenta da seguinte forma:

Acompanhando a evolução da tecnologia e consequentemente da forma de organização das empresas e instituições, a Secretária foi gradativamente acumulando novas funções, como a participação em reuniões, execução de tarefas mais gerenciais, e finalmente o estágio atual em que a atuação do profissional atingiu um novo patamar, com responsabilidades mais sérias e importantes para a empresa, exercendo função de gestor de processos, de pessoas, de informações, de relacionamentos e até mesmo da própria carreira. Adicionalmente, Paes et. al (2015, p. 113) explicam que:

Compreende-se que a assessoria pode ser definida como uma forma particular e inerente à atuação do profissional de Secretariado, na qual é caracterizada como uma assistência executiva, multiplicadora e adjunta aos órgãos decisórios (Executivos, diretores, gerentes). Essa assessoria funciona como aconselhadora, orientadora e recomendadora de sugestões, planos e procedimentos, multiplicadora de processos e prestadora de serviços especializados na área de Secretariado, enquanto atividade-meio da organização.

Destaca-se ainda a influência exercida pelos Secretários nos processos de tomada de decisão. Ligados diretamente à presidência ou diretoria, eles estão a par do que ocorre na empresa, em todos os níveis organizacionais, podendo tornarem-se assessores e facilitadores dos processos decisórios, participando ou influenciando os gestores em suas ações.

Para este profissional, na era digital, globalizada, faz-se necessária a busca por aperfeiçoamento, desenvolvimento técnico e pessoal, para obter a alta performance exigida pelo mercado. Assim, é preciso observar como é a profissão de Secretariado Executivo, como ela se desenvolve e quais serão seus rumos no futuro.

Paes et al $(2015$, p. 103) pontuam: "Observa-se que, diante do crescimento do mercado de trabalho, o Secretário também teve de evoluir em sua atuação profissional, deixando de ser um executor de atividades para delegar e gerenciar processos, informações e networking com seus stakeholders." 
Nesse contexto evolutivo, Saldanha (2005, p. 11) afirma: “As mudanças tecnológicas, sociais e políticas geram alterações nas formas de gestão das instituições públicas e privadas. Isto requer um profissional preparado e atento às mudanças nas técnicas, procedimentos e atividades ligadas às suas responsabilidades e ao seu desempenho."

Portanto, para que as empresas reconheçam o profissional de Secretariado como apto a desempenhar variadas funções, inclusive as de maior complexidade, é preciso que ele demonstre na prática as mudanças que a teoria reivindica para a área.

\section{Competências Secretariais}

As competências estão relacionadas com conhecimento, habilidade e atitude (CHA), assim caracterizadas na literatura. Estas qualidades precisam estar agrupadas para que um indivíduo possa desenvolvê-las. Essas três dimensões (CHA) estão interligadas e significam, em outras palavras, ter o conhecimento para fazer algo, saber fazer e exercer a ação de fazê-lo.

Durante a revisão da literatura, como parte da triangulação de dados deste artigo, foi realizado um breve levantamento bibliográfico sobre as competências secretariais destacadas nas pesquisas da área, seguido da análise de conteúdo categorial (Bardin, 2011), e do conteúdo de artigos do Secretariado que trataram sobre as competências deste profissional. Considerando as competências citadas em pelo menos 2 (dois) artigos como relevantes. Após comentários sobre os principais achados desta revisão, as competências são então resumidas na tabela 1.

Uma descrição destas competências secretariais é apresentada por Ribeiro (2005, como citado em Barros et al, 2013, pp. 35-36). Segurança profissional é a certeza da capacitação e o bom senso, determinados pelo equilíbrio emocional. Além disso, ser confiável vai além da discrição, pois é a capacidade de absorver uma tarefa e levá-la até o fim. Além de ser amistoso, principalmente quando se trabalha assessorando vários Executivos. $\mathrm{O}$ autor cita ainda outras características, como ser responsável, que representa o bom desempenho do profissional competente; ser leal também à empresa, e não somente ao Executivo; e ser sincero, trabalhar com a verdade.

Ribeiro (2005, como citado em Barros et al, 2013, p. 35-36) acrescenta que ser cooperador também é uma característica. A capacidade de cooperar torna-se fundamental ao trabalho de uma equipe, assim como ter mente aberta, pois é preciso aprender a ter equilíbrio na tomada de decisões, a fim de que não se assuma uma postura antiprofissional de um juiz arbitrário e inflexível; afinal, ser estável, é procurar manter o equilíbrio e, assim, trabalhar com o bom senso acima de tudo.

Por fim, ter capacidade de comunicação e persuasão é destacada pelo autor acima, pois o circuito comunicativo é pré-requisito para assegurar o sucesso na caminhada de um bom profissional. E persuasão éa capacidade de convencer os outros, não para tirar proveito das situações, mas para a obtenção da melhoria na qualidade empresarial.

Vale destacar que o Secretário engloba, ainda, atribuições, competências e responsabilidades em nível gerencial, elementos que ampliam as possibilidades de atuação nas diferentes estruturas organizacionais, dentre 
as quais estão: pensamento estratégico, capacidade de identificar oportunidades de crescimento, inovar e elaborar objetivos na organização, como afirmam Moreira et al (2016, p. 54 e 55).

Além disso, a habilidade comunicacional é o pilar nas relações de trabalho para negociações, comprovações e influência das pessoas, com o qual o Secretário Executivo lida, é o que preceitua Schumacher et al (2013, p. 55) quando argumentam que: "Ainda temos mais um grande desafio profissional que é desenvolver a habilidade de comunicação que é exigido como um dos requisitos essenciais para este profissional, pois tem como atividade cotidiana expressar-se de forma oral e escrita corretamente."

Moreira et al, (2016) elencam em seus estudos as competências contemporâneas dos profissionais de Secretariado Executivo, das quais se destacam as seguintes: liderança, iniciativa, ética profissional, bom senso, conhecimento da empresa, tomada de decisões e atuação como agente facilitador.

Em outros campos, o profissional de Secretariado tem atuado na área da gestão. Sendo assim, esta é outra competência destacada por Barros et al (2013, p. 27), que afirmam: "O profissional de Secretariado Executivo tem se desenvolvido e evoluído a ponto de não mais executar somente as atividades técnicas inerentes ao cargo. Têmse profissionais executando as mais diversas atividades incluindo-se as atividades de gestão."

Para Lima e Cantarotti (2010), as competências secretariais abrangem negociações, gerenciamento de informações, funções gerenciais como planejamento, organização, controle e direção, gestão secretarial e comunicação. Além das autoras já citadas, outros teóricos citaram estas mesmas competências do profissional de Secretariado, ou seja, as competências têm destaque em diferentes visões e áreas de atuação.

Adicionalmente, Almeida et al (2018, p. 8) elucidam que: “A negociação envolvendo parceiros; o grau de exigência com negociações frente a clientes internos e externos, a continuidade da apresentação de propostas de negociação; e se negocia com constância com agências de viagens, hotéis, buffets e outros segmentos".

Para sustentar as competências do profissional de Secretariado, os artigos 4ํㅜ e 5으 da Lei 7.733/85 (modificada pela Lei 9.261/96), que regulamenta a profissão, definem as atividades e atribuições a serem realizadas por esse profissional.

A tabela 1 apresentada a seguir consolida as principais competências deste profissional, segundo a literatura. Ela foi dividida em competências humanas, as quais representam a capacidade para lidar com as pessoas, de forma a compreendê-la, ajudando-a por meio do diálogo e da persuasão; e competências técnicas, que são os conhecimentos em conjunto com a habilidade, que formam a competência técnica, ou seja, a forma de condução e execução de atividades.

\section{Tabela 1}

Competências do Profissional de Secretariado

Competências Humanas Fontes

Inteligência Emocional

Relação Interpessoal

Eficiência
Barros et al (2013); Leal e Dalmau (2014) Moreira et al (2016).

Lima e Cantarotti (2010); Leal e Fiates (2013). Moreira et al (2016).

Lima e Cantarotti (2010); Leal e Fiates (2013). Moreira et al (2016). 
Competências Humanas

Flexibilidade

Autonomia

Competências Técnicas

Raciocínio Lógico

Organização

Gestão Secretarial

Atendimento (clientes internos e externos)

Negociação

Redação de textos oficiais

Gerenciamento de informações

Facilitador

Multifuncional
Fontes

Lima e Cantarotti (2010); Leal e Dalmau (2014) Moreira et al (2016).

Leal e Fiates (2013); Moura e Sobral (2014); Leal e Dalmau (2014).

Fonte

Moreira et al (2016); Camargo e Barbero (2018).

Lima e Cantarotti (2010); Aguilar e Souza (2018).

Lima e Cantarotti (2010); Leal e Dalmau (2014); Aguilar e Souza (2018).

Lima e Cantarotti (2010); Leal e Fiates (2013); Almeida et al 2018

Lima e Cantarotti (2010); Barros et Al (2013); Todorov et al (2013); Leal e

Dalmau (2014); Almeida et al 2018.

Lima e Cantarotti (2010); Leal e Fiates (2013); Leal e Dalmau (2014); Moura e

Sobral (2014); Moreira et al (2016).

Lima e Cantarotti (2010); Todorov et al (2013); Moreira et al (2016); Camargo

e Barbero (2018).

Barros et al (2013); Moreira et al (2016).

Lima e Cantarotti (2010); Leal e Fiates (2013); Leal e Dalmau (2014).

Sendo assim, de acordo com a pesquisa, o profissional de Secretariado, sustentado pelo conhecimento obtido na graduação, deveria possuir competências de grande valor. Essas competências contribuem para a assessoria em níveis complexos, ou seja, além da assistência pessoal e técnica, exercendo funções que exigem mais conhecimento do profissional que executa essa atividade.

Ele deveria, considerando os conhecimentos acadêmicos, executar atividades de níveis estratégico e de gestão e, segundo as autoras Aguilar e Souza (2018, p. 5): “A atuação do profissional de Secretariado, seja como gestor, empreendedor, consultor ou assessor, é permeada, principalmente, pela atuação no nível analíticosimbólico, aqui entendido como a capacidade de articular conhecimentos, competências e habilidades no sentido de desenvolver ações positivas no ambiente de trabalho."

Considerando a perspectiva delineada acima, apresentamos a metodologia traçada para este estudo, bem como as reflexões dos dados encontrados no estudo de caso em tela, finalizando-o com as considerações finais.

\section{Metodologia}

Trata-se de uma pesquisa de abordagem qualitativa, com objetivos descritivos, que segue procedimentos de estudo de caso (Yin, 2010). Segundo Yin (2010, p. 39), “(...) o estudo de caso é uma investigação empírica que investiga um fenômeno contemporâneo em profundidade e em seu contexto de vida real."

No estudo de caso das ciências sociais aplicadas, é analisada a situação de um ambiente, quais suas características, que pessoas atuam nesse local, suas formas de trabalho, ou de agir, em qual realidade estão inseridos, quais serão as formas de coleta de dados, que estratégia de análise será utilizada, e qual o tema será discutido. Nesse contexto, Marques et al (2014, p. 29) afirmam que: “O estudo de caso é um tipo de pesquisa de campo que busca o entendimento da realidade sobre determinado tema." A triangulação exigida para um estudo de caso foi realizada a partir de dados de observação participante, entrevistas e análise bibliográfica. 
Inicialmente, foi realizada uma observação participante. De acordo com Yin (2010), na observação participante o pesquisador não é um observador passivo, mas sim participativo de fato. Neste paper o pesquisador foi observador participativo das atividades diárias da Secretária Executiva da organização estudada, que assessorava três superintendentes, na realização de algumas destas atividades, com vistas a compreender as competências colocadas em prática e o nível de autonomia deste profissional. Ainda, foram analisadas as atividades de duas outras secretarias da diretoria, com os mesmos objetivos.

A observação foi realizada durante 45 dias úteis, no período da manhã. A análise e participação nas rotinas de trabalho objetivaram conhecer o ambiente em que o sujeito observado estava inserido, além de compreender as principais atividades de sua rotina. Também foram analisadas atividades extras com os seguintes parâmetros: quem requisitava (cargo), quais contatos a Secretária observada tinha com os demais departamentos e com que frequência os contactava. Para completar a análise, foi verificada e avaliada a complexidade das atividades, com o objetivo de identificá-las como atividades técnicas ou não, quais meios e conhecimentos utilizavam para realizá-las, etc. Além disso, buscou-se avaliar o nível de autonomia para realização de atividades ou para implementação de mudanças.

Foram ainda observadas quais tipos de atividades técnicas secretariais eram desempenhadas. Por exemplo, ligações realizadas e recebidas; materiais e relatórios preparados, informações dadas e recebidas, organização de reuniões e eventos etc.

Após a observação participante, foram realizadas entrevistas in loco com os três superintendentes assessorados pelas Secretárias Executivas, por meio de gravador de voz, seguindo o guia de entrevista apresentado na Tabela 2.

Tabela 2

Entrevista

Questões

1 - Qual a sua formação acadêmica? Qual cargo você ocupa atualmente na empresa? Há quantos anos você trabalha na empresa e qual a sua experiência anterior nesta? Você possui experiência de trabalho anterior ao seu ingresso na empresa? Quais?

2 - No geral, quais são as atividades que você realiza?

3 - Você definiria sua função como de assessoria à diretoria? Ou teria melhor forma de defini-la?

4 - Como as informações são passadas para você em relação ao que ocorre dentro de toda a empresa?

5 - Quais decisões você pode tomar?

6 - Quais os conhecimentos (técnicos e teóricos, de formação etc.) você acha importante para a sua atuação?

7 - Quais competências (por exemplo, características como profissional) você acha importante para sua atuação?

8-O que foi decisivo durante a sua carreira para chegar ao cargo que tem hoje?

9 - A respeito do Secretariado Executivo, como você vê essa profissão?

10 - Sobre as suas atividades realizadas no dia a dia, quais você acredita que poderiam ser direcionadas para o Secretário

Executivo?

Sobre os discursos obtidos nas entrevistas, foi aplicada a análise de conteúdo definida por Bardin (2011), fundamentada na técnica de análise categorial, preocupando-se com a ocorrência/não ocorrência dos temas e 
de seus indicadores definidos. Apesar de não ser uma metodologia rígida, a operacionalização desta análise de conteúdo se deu seguindo as 3 fases propostas por Bardin (2011, p. 124): a pré-análise; a exploração do material; e o tratamento e interpretação dos resultados.

Por fim, foi analisado o conteúdo (Bardin, 2011) de publicações científicas acerca das competências do profissional de Secretariado Executivo, com o objetivo de enumerar as principais competências reconhecidas pelos teóricos na área. O resultado desta revisão foi apresentado no referencial teórico deste artigo e na tabela 1.

\section{Resultados e Discussões}

Definidos os objetivos e aportes teóricos deste trabalho, enfatizando a análise das competências do profissional de Secretariado, em comparação com as competências da superintendência da organização-caso estudada, apresenta-se a análise dos dados levantados.

Este estudo enfatiza que, em teoria, conforme resultados da análise bibliográfica apresentada na tabela 1, o profissional de Secretariado tem conhecimento para desenvolver atividades complexas, além das técnicas secretariais, visando contribuir estrategicamente na empresa. Entretanto, destaca-se na observação participante a dificuldade da atuação prática, no cotidiano da empresa estudada.

Após a transcrição, pré-análise, exploração do material e interpretação dos resultados dos áudios gravados nas entrevistas com os superintendentes, foi possível identificar as principais atividades realizadas por cada um deles, a trajetória de suas experiências e conhecimentos adquiridos dentro e fora da empresa estudada.

Esses profissionais atuam como ponte das áreas estratégica-operacionais da organização. Eles apresentam uma carreira com experiência profissional de mais de 10 anos, atuando em diversos programas de melhorias dos processos empresariais e certificações de qualidade, além de estarem há muitos anos na empresa estudada, o que contribuiu fortemente para que exercessem os cargos de superintendentes.

Em se tratando das competências científicas dos profissionais estudados, a base para iniciar a carreira profissional foi a graduação nas áreas de Administração de Empresas ou Financeira, Gestão de Projetos e Agronomia. E as habilidades pessoais requeridas na atuação destes profissionais, destacadas nas entrevistas foram: o bom relacionamento interpessoal, visão do negócio, comunicação e negociação, capacidade de liderança, autoconfiança e autoconhecimento.

Em relação às competências dos superintendentes entrevistados, as mais destacadas foram: proatividade, gestão, inteligência emocional, paciência, conhecimento, iniciativa e capacidade de delegar tarefas. Conforme trecho retirado da entrevista realizada: "O que priorizamos muito na empresa é a iniciativa, proatividade, pois o mundo de hoje pede isso. As informações são de fácil acesso, e isso ajuda muito nas atividades do dia a dia." (Superintendente 1)

Quanto às competências da literatura sobre os profissionais de Secretariado, os resultados encontrados e apresentados na tabela 1 são, em muitos aspectos, semelhantes às competências apontadas pelos superintendentes. Conforme os pesquisadores da área secretarial, este profissional “[...] ainda é um negociador, 
programador de soluções, empreendedor, mostrando iniciativa, proatividade, comprometimento e participando em inúmeras atividades no ambiente de trabalho" (Lasta \& Durante, 2008, p. 54).

Os superintendentes atuam com autonomia, tomando decisões sobre valores de vendas de produtos, formação de equipes, além de coordenar auditorias internas, novos negócios, tomada de decisão sobre expansão das unidades, controle da fabricação dos produtos. De acordo com o entrevistado, a respeito da tomada de decisões:

Na superintendência a gente tem bastante autonomia de trabalho. É mais fácil eu falar para você qual [decisão] que eu não posso tomar. Eu não posso tomar a decisão de fazer um grande investimento sem antes passar pelo conselho de administração, eu não posso tomar uma decisão de comprar uma estrutura fora sem antes ter passado pela aprovação do conselho de administração. Então são essas decisões com relação a investimentos. Com relação à tomada de decisão de comprar, vender e colocar preço de produtos no quadro ou comprar insumos para revender, essas decisões a gente tem total autonomia para fazer.

(Superintendente 1)

Em alinhamento com este tipo de atuação, a literatura afirma que o profissional de Secretariado teria capacidade para lidar com negociação, com as competências fundamentadas, segundo Quinn et al. (2003, como citado em Barros e Silva, 2013, p. 34): “Negociação de acordos e compromissos; contribuição por meio da apresentação de ideias e sugestões e opiniões para tomada de decisão em reuniões, com pares e subordinados".

Os estudos analisados, quanto às competências do profissional de Secretariado, apontam demais aptidões que o mesmo deveria possuir, como Leal e Dalmau (2014, p. 166) destacam: “Comprometimento; flexibilidade/ resiliência/adaptação; empatia; bom relacionamento interpessoal; ética profissional; liderança; paciência; equilíbrio emocional; bom humor; iniciativa/proatividade; bom senso; postura; calma; profissionalismo; trabalho em equipe; discrição; capacidade de comunicação; habilidade para resolver problemas; criatividade."

Além das competências comportamentais, foram destacadas pelos autores citados as competências técnicas, que são:

Noções de administração pessoal e financeira; técnicas secretariais; conhecimento de trâmites, normas e resoluções; coordenação de eventos e ações cerimoniais e protocolares; mediação de conflitos; domínio da norma padrão culta; redação oficial; administração do tempo; utilização de recursos e softwares de comunicação e informação disponíveis; raciocínio lógico; gestão de arquivos e processos; conhecimento de línguas estrangeiras (Leal \& Dalmau, 2014, p. 166).

Entretanto, foi observado que os profissionais de Secretariado Executivo, na empresa estudada, não atuam no campo estratégico dentro da empresa, como sugerem as abordagens teóricas estudadas. Conforme observação participante, o que foi examinado durante o período de estudo revela que o profissional atua na empresa estudada de forma técnica, desenvolvendo, na maior parte do tempo, atividades operacionais. Estas atividades desenvolvidas observadas resumem-se em: 
- Atendimento diário de telefonemas internos e externos para marcar compromissos com os superintendentes e realização de reservas de salas de reuniões;

- Impressão de relatórios, que eram analisados diariamente pelos superintendentes, e impressão de um relatório semanal para reunião de diretoria que constava o faturamento semanal da empresa;

- Controle da agenda de compromissos dos superintendentes: reuniões, visitas e viagens;

- Preparo da sala de expediente e de reunião (ligar a televisão para exibição das informações diárias sobre as vendas da empresa; ligar o ar-condicionado e as luzes para os participantes internos e externos etc.);

- Emissão e arquivamento de relatórios com informações de gastos das viagens (quilometragem, alimentação e hospedagem) dos superintendentes. Os superintendentes realizavam algumas viagens com o cartão corporativo e ao retornarem era necessário fazer os lançamentos no sistema;

- Solicitação ao financeiro para pagamento de boletos do cartório;

- Atendimento aos colaboradores dos outros departamentos. Com frequência, colaboradores precisavam resolver pendências com os superintendentes, assim se dirigiam às secretarias para fazer o encaminhamento.

- Por fim, era realizada a organização de contatos telefônicos, principalmente relacionados a visitas de outras empresas à organização. Organização de todos os cartões de visita para manter os contatos acessíveis. E organização de presentes para visitantes da cooperativa.

Ao triangular as competências do profissional de Secretariado Executivo, com base na análise bibliográfica de publicações da área, as atividades desenvolvidas na prática secretarial na empresa estudada e as atividades realizadas pelos superintendentes, constatou-se que, no caso estudado, o profissional de Secretariado ainda precisa adquirir conhecimento para assessorar aos Executivos em níveis mais complexos e estratégicos da empresa, o que é afirmado pelos superintendentes na entrevista:

Tem coisas que eu não tenho como passar para vocês [referindo-se aos Secretários Executivos]. A gente sabe que eu tenho que decidir, que tenho que atender meu gerente, eu tenho junto com ele tomar as decisões, mas a gente entende que as vezes usamos pouco vocês. A gente se tornou um pouco independente também nesses aspectos. Mas tem coisas que vocês podem nos ajudar, mudar alguns modelos de reunião. Algo mais interativo, produtivo, mais estratégico, e esse é o desafio, a estratégia. Vocês se inserirem na estratégia. A gente usa muito assessoria de empresas que presta serviços pra gente para preparar apresentações, especial as formais para conselho, assembleia, essas coisas acho que vocês podem ir avançando, só que vocês vão precisar de mais conhecimento, como indicadores econômicos, indicadores financeiros, de dólar, mercado, bolsa, porque isso é importante. São esses tipos de informações que vem para as apresentações e talvez vocês vão ter que pensar sobre isso, noções de mercado externo. Isso é uma pequena dica. Eu diria para você que entendo que o curso é importante e que vocês tem que estar cada vez mais antenados com relação a esse mercado, a essas novas profissões, funções, porque os 
Executivos vão ficando desgarrados dos locais em que eles estão, onde eles fazem o trabalho deles e vocês vão ter que se preocupar com o que eles estão fazendo. (Superintendente 1)

A partir dos dados apresentados, conclui-se que as competências do profissional de Secretariado evidenciadas na literatura da área coincidem, e são bem semelhantes, às competências profissionais de assessorias complexas, como observado nos relatos/discursos dos superintendentes da organização entrevistados. Contudo, as funções exercidas na prática por Secretários Executivos na organização são mais voltadas a atividades técnicas e não exigem as competências necessárias das assessorias complexas, tão enfatizadas pela literatura.

Ao comparar a atuação das Secretárias Executivas observadas com as atividades desempenhadas pelos superintendentes, é possível compreender que estes desenvolvem atividades estratégicas na empresa, agindo como cogestores, intermediando o nível estratégico e o nível operacional na organização; enquanto a Secretária Executiva se ocupa das tarefas mais operacionais de rotina técnica de assistência pessoal. Sendo assim, no caso estudado, o que é afirmado na teoria não está sendo aplicado na prática.

\section{Considerações Finais}

Esta pesquisa buscou verificar, em um estudo de caso, se o Secretário Executivo estaria apto a assumir funções de assessoria em níveis complexos, como cogestor e tomador de decisão na assessoria a altos Executivos. Para isso, analisou-se a função e as competências exigidas dos profissionais no cargo de superintendentes em uma organização de médio porte. Considerando que tais profissionais são gestores, com poder de decisão estratégica e operacional, e que assessoram o mais alto nível de diretoria executiva da organização, configurando uma função semelhante às de assessorias complexas.

Assim, buscou-se compreender qual a capacitação exigida nestas funções de assessorias complexas na organização e confrontá-las com a capacidade do profissional de Secretariado defendida pela teoria, bem como com a capacidade demonstrada na prática secretarial exercida na empresa. Esta capacidade dominada pelo profissional seria operacionalizada por meio de suas competências.

Ao comparar as competências necessárias nas assessorias complexas com as do profissional de Secretariado Executivo, identificadas pela teoria e observadas na atuação dos Secretários na organização estudada, observou-se que estes profissionais desempenham atividades operacionais de nível técnico, o que não condiz com a teoria sobre as competências relacionadas a este profissional.

Por meio da observação das atividades rotineiras da Secretária Executiva e dos gestores na empresa estudada, foi possível identificar como eram desenvolvidas estas atividades e como elas eram transmitidas até a profissional de Secretariado, para então serem executadas. As entrevistas realizadas com os superintendentes completaram a análise sobre as atividades realizadas por eles, viabilizando a compreensão sobre como os cargos e as atividades eram organizadas e colocadas em prática pelos superintendentes, ou seja, a partir de quais competências. 
Pelos resultados obtidos na análise bibliográfica das publicações secretariais, o Secretário Executivo estaria apto a assumir funções de assessoria em níveis complexos, como gestor e tomador de decisão na assessoria a executivos, por suas competências. Com a análise bibliográfica, reforça-se essa hipótese.

Porém, o que ficou evidente, no caso estudado, a partir das observações e entrevistas realizadas e analisadas, é que o profissional de secretariado na empresa não atua em tais assessorias complexas, limitandose a tarefas mais técnicas e operacionais. Observou-se que o Secretário Executivo necessita se especializar em processos que são realizados pela empresa e na área de atuação desta, para que possa tomar decisões assertivas e contribuir com os objetivos da empresa. Especialização essa que engloba desde aprofundamento de conhecimentos na graduação. Possuir melhores noções sobre economia, finanças e mercado. Além de informações específicas que colaborem com o entendimento do segmento em que a organização atua.

Diante do estudo realizado, o que se tem observado é que o futuro da profissão de Secretariado só será promissor se o profissional assumir as competências defendidas pela literatura, ou seja, tornar-se apto para funções de assessorias complexas.

Isso se torna evidente, pois o profissional é visto na empresa estudada como um assistente técnico, o qual limita-se a realizar atendimentos telefônicos, filtrar ligações, controlar a agenda dos diretores e organizar viagens. Essas atividades podem facilmente ser substituídas por tecnologias ou pela própria independência dos gestores. Independência essa destacada pelos superintendentes, durante as entrevistas.

O profissional de Secretariado precisa ganhar seu espaço nas empresas, colocando em prática os conhecimentos adquiridos na graduação, fazendo especializações, ampliando seus conhecimentos de forma constante, estudando a organização na qual atua. Somente desta maneira realizará atividades complexas, essenciais e insubstituíveis.

As conclusões obtidas com a pesquisa apresentada são relacionadas à organização investigada, ou seja, são resultados de um estudo de caso específico, não sendo generalizáveis. Não é possível afirmar que em todos os segmentos empresariais o profissional de Secretariado desenvolve suas atividades no formato retratado. Entretanto, a prática vem demonstrando uma tendência neste sentido.

Sugere-se investigar outros segmentos de empresas e observar como o profissional de Secretariado se desenvolve e compará-los com as dos gestores de nível médio, ou outros profissionais atuando em funções de assessoria complexa. Assim, poderia ser verificado em diferentes situações como as atividades secretariais são desenvolvidas e em que níveis (estratégico, operacional e técnico).

Os achados deste trabalho instigam caminhos para pesquisas futuras, no sentido de aproximar a teoria da prática. Ou seja, pesquisas que elucidem se os Secretários Executivos têm espaço e capacitação para atuação prática adequada às competências atribuídas a este profissional pela literatura. Além disso, cabe analisar o desenho curricular das graduações de Secretariado Executivo, para verificar se os conteúdos ensinados fazem sentido para uma atuação secretarial que busca preparação para funções de assessorias complexas. 


\section{Referências}

Almeida, W. A. G. de; Borini, F. M. \& Souza, E. C. P. (2018). Competências Comportamentais dos Profissionais de Secretariado: o impacto da atuação internacional da empresa.Revista de Gestão e Secretariado, 9 (1), 1-17. https://doi.org/10.7769/gesec.v9i1.632

Aguilar, L. de \& Souza, R. B. de. (2019). Uma breve análise do potencial da formação continuada como instrumento para o desenvolvimento das competências e habilidades requeridas pelo mercado de trabalho.Revista de Gestão e Secretariado, 10 (1), 1-25. https://doi.org/10.7769/gesec.v10i1.701

Bardin, L. (2011). Análise de conteúdo. São Paulo: Edições.

Barros, C. de M. P.; Silva, J. S. da; Lima, G. A. de \& Brito, D. G. S. (2013). As competências gerenciais desenvolvidas pelos Secretários Executivos.Revista de Gestão e Secretariado,4 (2), 25-47. https://doi.org/10.7769/gesec. $\underline{\mathrm{v} 4 \mathrm{i} 2.131}$

Camargo, M.; Nascimento, L.; Buhrer, V.; Martinelli, G. \& Bahls, T. (2015). A evolução da área secretarial às ciências da assessoria.Revista Expectativa, 14(14). https://doi.org/10.48075/revex.v14i1.9355

Camargo, F. A. \& Barbero, E. R. (2018). Competências financeiras: a importância percebida por profissionais de Secretariado.Revista de Gestão e Secretariado, São Paulo, 9 (2), 45-71. https://doi.org/10.7769/gesec. $\underline{\mathrm{v} 9 \mathrm{i} 2.765}$

Choo, C. W. (2003). A organização do conhecimento: como as organizações usam a informação para criar significado, construir conhecimento e tomar decisões. São Paulo: Senac São Paulo.

Durante, D. G. \& Fávero, A. A. (2009). Gestão secretarial: formação e atuação profissional.Santa Maria: UPF Editora.

Durante, D. G. (2012). Pesquisa em Secretariado: cenários, perspectivas e desafios.Passo Fundo: Universidade de Passo Fundo.

Lasta, A., \& Giareta Durante, D. (2011). A GESTÃO SECRETARIAL NO CENÁRIO ORGANIZACIONAL CONTEMPORÂNEO. Secretariado Executivo Em Revist@, 4(4). Recuperado de http://seer.upf.br/index.php/ser/article/view/1768

Leal, F. G. \& Dalmau, M. B. L. (2014). Análise das competências secretariais requeridas pela Universidade Federal de Santa Catarina em comparação ao perfil profissiográfico do Secretário Executivo.Revista de Gestão e Secretariado, 5 (3), 143-174. https://doi.org/10.7769/gesec.v5i3.289

Leal, F. G. \& Fiates, G. G. S. (2013). Competências dos Secretários-Executivos de uma Universidade Pública Federal: Uma Análise a partir da perspectiva dos gestores.Revista de Gestão e Secretariado, 4 (3), 30-57. https://doi. org/10.7769/gesec.v4i3.216

Lima, T. F. \& Cantarotti, A. (2010). A formação e a construção de competências para a atuação do profissional de Secretariado Executivo-um estudo de caso em uma empresa júnior.Revista de gestão e Secretariado, 1 (2), 94-122. https://doi.org/10.7769/gesec.v1i2.17

Lei N. 7.377, de 30 de setembro de 1985. Dispõe sobre o exercício da profissão de Secretário e dá outras providências. Brasília: Senado Federal. Recuperado de http://www.planalto.gov.br/ccivil 03/leis/ 
Lei N. 9.261, de 10 de janeiro de 1996. Dispõe sobre o exercício da profissão de Secretário e dá outras providências. Brasília: Senado Federal. Recuperado de http://www.planalto.gov.br/ccivil 03/leis/L9261.htm\#art1

Marques, K. C. M.; Camacho, R. R. \& Alcantara, C. C. V. de. (2015). Avaliação do rigor metodológico de estudos de caso em contabilidade gerencial publicados em periódicos no Brasil.Revista Contabilidade \& Finanças, 26 (67), 27-42. https://doi.org/10.1590/rcf.v26i67.98096

Moreira, K. D., Rodrigues, L. M. A., Vale, J. C. F. do, \& da Rosa, M. H. (2016). As competências contemporâneas do Secretário Executivo e a relação com as competências do Middle Manager. Revista de Gestão e Secretariado, 7(1), 45-66. https://doi.org/10.7769/gesec.v7i1.400

Moura, M. do C. de S. \& Sobral, M. F. F. (2014). Gestão por competências com uso da metodologia multicritério na avaliação de profissionais de apoio administrativo de um Call Center.Revista de Gestão e Secretariado, 5 (3), 1-27. https://doi.org/10.7769/gesec.v5i3.308

Nonato Junior, R. (2009). Epistemologia e teoria do conhecimento em Secretariado Executivo: a fundação das ciências da assessoria.Fortaleza: Expressão Gráfica.

Paes, R. V. O.; Antunes, C. K. de S. A.; Santiago, C. da S. \& Zwierzikowski, M. R. (2015) Novas formas de atuação do profissional de Secretariado Executivo. Revista de Gestão e Secretariado, 6 (1), 99-125. https://doi. org/10.7769/gesec.v6i1.318

Santos, M. F. S., \& Cruz, S. S. (2012). A atuação do profissional de Secretariado Executivo graduado pela Universidade do estado do Pará. XVIII CONSEC.

Saldanha, L. C. D. (2013). O mercado de trabalho e a formação do profissional de Secretariado Executivo.Revista Expectativa, 4 (1), 9-19.

Schumacher, A. J.; Portella, K. C. A. \& Borth, M. R. (2013). Ferramentas do Secretário Executivo.Cuiabá: Dos Autores.

Todorov, M. do C. A.; Kniess, C. T. \& Chaves, M. S. (2013). As competências do profissional de Secretariado na implantação de projetos sustentáveis. Revista de Gestão e Secretariado, 4 (3), 189-209. https://doi. org/10.7769/gesec.v4i3.275

Yin, R. K. (2010). Estudo de caso: planejamento e métodos. 4a ed. Porto Alegre: Bookman. 